Ethiopian Journal of Environmental Studies \& Management 9(5): 604 - 612, 2016.

ISSN:1998-0507

Submitted: May 08, 2016

doi: http://dx.doi.org/10.4314/ejesm.v9i5.7

Accepted: September 14, 2016

\title{
DETERMINANTS OF INFANT IMMUNIZATION COVERAGE IN MIGORI COUNTY, NYANZA REGION, KENYA
}

\author{
MUKUI, S.J., ${ }^{1}$ MUTUA, E.M., ${ }^{1}$ GITONGA, M.M., ${ }^{1}$ CHEPTUM, J.J., ${ }^{1}$ NDAMBUKI, J.M. ${ }^{1}$ \\ AND KOIMA, W.2 \\ ${ }^{1}$ School of Health Sciences, Dedan Kimathi University of Technology, P.O Box 657 - \\ 10100, Nyeri, Kenya \\ ${ }^{2}$ Department of Research,Training Management and Community Linkages, Dedan \\ Kimathi University of Technology, P.O Box 657 - 10100, Nyeri, Kenya
}

\begin{abstract}
The main objective of this study was to examine determinants of infant immunization coverage in Migori County; Nyanza. Migori-Nyanza is the regions of disparities that continue to register low rates of immunization coverage in Kenya. The coverage rate was measured against Kenya's and World Health Organization target percent for achieving herd immunity and improved child survival. Immunization coverage rates are accepted as an indicator of the performance and adequacy of a Country's Health Service Systems. A descriptive study of 446 households sampling units was conducted in January 2013. The households were randomly selected from four demand areas. Methods of data collection were: interviewer administered questionnaires, key informant interviews and homogeneous focus group discussions. Respondents were mothers aged 19- 45 years with a child less than five years of age. The results indicated that fully immunized infants were 70\%; a fully immunized infant was one who received one dose of BCG, four doses of Oral Polio Vaccine (OPV), three pentavalents, and one dose of measles vaccine before reaching one year of age. The results further indicated that:- $80 \%$ of infants had their birth polio and BacillusCalmette Guerin (BCG) within the first two weeks of life, $78 \% 3^{\text {rd }}$ pentavalent and $4^{\text {th }}$ polio at 14 weeks of life and $77 \%$ measles at 9 months. Measles and third dose of pentavalent immunizations are used as indicators of a fully immunized child. The determinants of immunization coverage that were identified from the study included: means of transport to health facilities, religious affiliation, home delivery and not attending postnatal clinics, mothers' lack of knowledge on dangers of childhood diseases and hostile attitudes shown by service providers to the mothers. In conclusion there was under coverage of immunization in the region. The recommendation was that the health service providers need to in- cooperate both outreach and mobile immunization services into their current static module.
\end{abstract}

Key Words: Immunization coverage, Infant mortality, immunization Indicators, Migori, Kenya

\section{Introduction}

Millions of children die globally from vaccine preventable diseases. Immunization is a primary health care element and is considered the most costeffective preventive health service for children. According to UNICEF (2010), immunization of children against vaccine

*Corresponding Author: Mukui, S.J.

Email: jendekamukui@gmail.com 
preventable diseases has made impressive contribution to reducing child deaths. Overall Immunization averts an estimated 2-3 million deaths of children in all age groups every year (WHO, 2012). Infant immunization has been regarded as one of the most important achievements of public health as well as an effective strategy of reducing child mortality rates. It has also been documented that immunization coverage is a key measure of immunization system performance (WHO, 2013). Immunization coverage levels and trends are also used to monitor the performance of immunization services locally and internationally (WHO, 2010). Infant and child mortality rates are key indicators of a child well being, child survival interventions and more broadly a Country's health status. Good health is a pre-requisite for socioeconomic development. Immunization coverage rates are accepted as an indicator of the performance and adequacy of a Country's Health Service Systems.

Kenya's immunization coverage target of children under 5 years is $90 \%$ (KDHS 2009), this is the level required to reach herd immunity and interrupt community transmission for all vaccine preventable diseases. However there are regional disparities with Nyanza continuing to register low rates of coverage which is lower than the National figures and increase child mortality rates (KDHS 2008-2009). Documented evidence by research such as the Kenya National Bureau of Statistics (KNBS 2011) multiple indicator cluster survey report in Nyanza Province showed that the percentage of fully immunized children was $70 \%$.
According to KNBS office, (Migori 2013), the under- one year (infants) comprised of $1.1 \%$ of the total population of 917,170 people (2009 census. Therefore in the county's integrated development plan2013-2017, there was a need to increase immunization coverage in order to reduce child mortality as enshrined in millennium development goal number four. This reason was the genesis of the partnership between Migori County, College of the Rockies and Dedan Kimathi University of Technology.

The main objective of this study was therefore to examine determinants of infant immunization coverage in Migori County; Nyanza with the view of establishing interventions towards addressing the same as part of the Maternal Access and Infant Survival for Health Advancement (MAISHA) Project. The aim of the project is to improve maternal and infant service delivery through retraining of staff on essential emergency obstetric care and the community health workers on strengthening immunization services among other basic services at the community level. The project is a joint venture between the College of Rockies in Canada and Dedan Kimathi University of Technology- Kenya.

\section{Methods}

\section{Description of Study Area}

The study was done in Migori County; confined to households in four demand areas namely: Ondong', Ogwedhi in Suba East, Nyamaraga and Godkwer in Suba West. Migori County is a County in the Nyanza Province of South-Western Kenya which is found between latitude $0^{\circ} 24^{\prime}$ and $0^{\circ} 40^{\prime \prime} \mathrm{S}$ and 
longitude $34^{\circ}$ and $34^{\circ} 50^{\prime \prime}$ East. The county has an altitude varying between $1140 \mathrm{~m}$ above sea level at the shores of Lake Victoria in Nyatike Sub-county to $4625 \mathrm{~m}$ sea level in Uriri Sub-county. The high altitude area has several undulating hills and plains stretching for about 20$70 \mathrm{~km}$.

The county has an inland equatorial climate modified by the effects of altitude, relief and the influence of the large body of water of Lake Victoria. The annual rainfall averages between 700 and $1,800 \mathrm{~mm}$. The Lake shore division experiences unreliable and poorly distributed rainfall. Temperatures show mean minimum of $24^{\circ} \mathrm{C}$ and maximum of $31^{\circ} \mathrm{C}$, with high humidity and a potential evaporation of 1800 to $2000 \mathrm{~mm}$ per year.

\section{Study Design and Data Collection}

A total of 446 households were randomly selected in four demand areas namely: - Ondong', Ogwedhi in Suba East, Nyamaraga and Godkwer in Suba West. Ethical standards were observed by having the proposal approved by the Kenyatta University research board and the National Council for Science and Research (Kenya).Also informed consent from respondents was obtained before they were engaged in the interviews.

A two stage sampling technique of probability random sampling was used; population proportionate to size and simple random. A cross- sectional descriptive survey design was used in which both quantitative and qualitative methods of data collection were used. The questionnaire administered method was used to collect quantitative data because it made face to face interview easy. The 446 sampled households were surveyed in January 2013. The respondents were mothers in their reproductive age (15-49 years) and with children less than five years of age. Data was obtained using a combination of verbal responses to structured questions, immunization records and recall when the records were not available. Qualitative data was obtained through Key informant interviews and homogenous male and female focus group discussions using an interview guide. Key Informant Interviews (KII) with healthcare administrators was also conducted on factors affecting immunization coverage in the demand areas using an interview guide. To ensure quality data was obtained supervisors ensured the questionnaires were completed fully before enumerators left the field.

The study was conducted to generate baseline information for the Maternal Access and Infant Survival for Health Advancement (MAISHA) project. This was a DFATD funded project implemented through the Dedan Kimathi University of Technology (DeKUT) and College of the Rockies, Canada collaboration (COTR).

\section{Data Analysis}

After data collection, cleaning was done both at the field and centrally before entry onto a computer programme was done. Descriptive and inferential statistics were used for data analysis using Stata version 11. Pearson's ChiSquare was used to determine associations between immunization coverage and identified variables (determinants). Using $95 \%$ confidence level, a value that was $<0.05$ was considered to be associated and a value that was $>0.05$ was considered not to be associated. 


\section{Results}

\section{General Characteristics}

The reproductive age concentration was between 18-35 years and there was no significant association between maternal age and child immunization coverage. The highest level of education a majority of the mothers had primary education (80\%). Inferential statistics did not show significant association between mothers level of education and immunization coverage. The surveyed mothers were mainly self employed $(42.2 \%)$ and housewives $51.47 \%)$; again there was no significant association between mother's occupation and immunization coverage.

\section{Overall Immunization Coverage}

The results indicated that the fully immunized children in the County were $70 \%$; a fully immunized child was one who got measles vaccine at or above nine months in addition to the three pentavalents and four oral polios. This finding showed under coverage because this was below Kenya's National target coverage of $90 \%$ and at least $80 \%$ coverage for Counties. Figure 1 (Full Immunization Coverage) illustrates the percentage of the County's coverage.

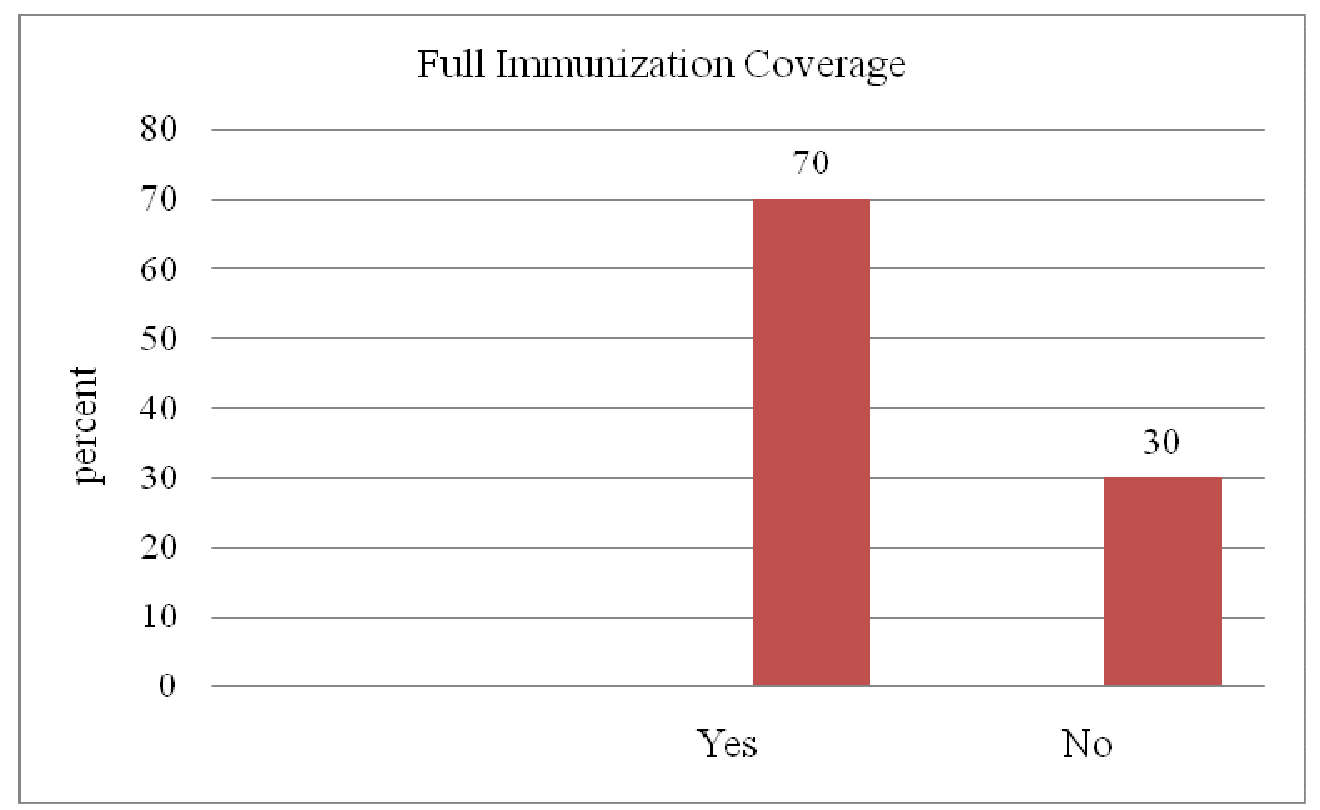

Figure 2: Immunization Coverage

The results from the survey further indicated the distribution of the coverage as follows: $80 \%$ of the children under five years had been given birth polio and Bacillus-Calmette Guerin (BCG) within the first two weeks of life; $60.3 \%$ had received first pentavalent and second polio at 6 weeks of life; $60.7 \%$ (224) had had $2^{\text {nd }}$ pentavalent and $3^{\text {rd }}$ polio at 10 weeks; 58.8 (207) \% had been given $3^{\text {rd }}$ pentavalent and $4^{\text {th }}$ polio at 14 weeks of life and $76.9 \%$ (254) for measles at 9 months. Measles and third dose of pentavalent immunizations are used as indicator of a child's full immunization; $76.9 \%$ is therefore below Kenya's National target coverage of $90 \%$, and at least $80 \%$ in each County. Figure 2 below 
(Distribution of Vaccine Coverage) coverage of the primary immunizations. indicates percentage distribution

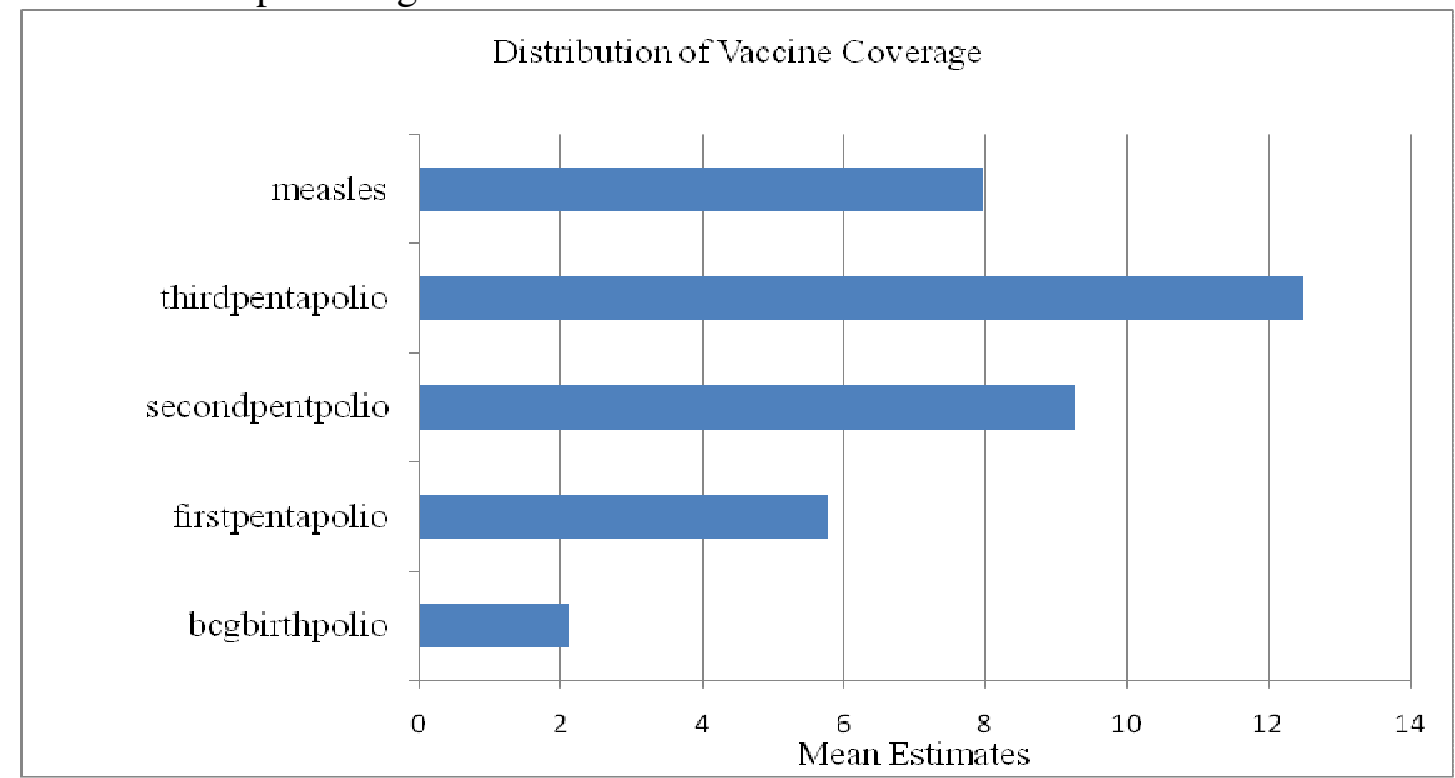

Figure 3: Vaccine Coverage

\section{Immunization Determinants Means of Transport}

The findings from quantitative methods indicated means of transport to immunization sites as one of the determinants of immunization coverage. The commonest means of transport was on foot $(88 \%)$; inferential statistics showed there was a significant association between a child's immunization coverage and mothers means of transport to the immunization site $(\mathrm{P}-$ Value $=0.044)$.

Nearly half of the mothers in their reproductive age (15-49 years) delivered their babies at home $(45 \%)$. Home delivery also determined immunization coverage. There was a significant association between full immunization of a child and home deliveries, P-Value = 0.024. In this regard the mothers who delivered at home did not get their children fully immunized. One of the mothers in the focus group discussion had this to say to this effect "home deliveries are preferred because the traditional birth attendants are friendly and so we don't use other services as required because we shy away from the health service providers" (FGD participant); Figure 3 below (Place of Last Delivery) illustrates the percentages of home and health facility deliveries. 


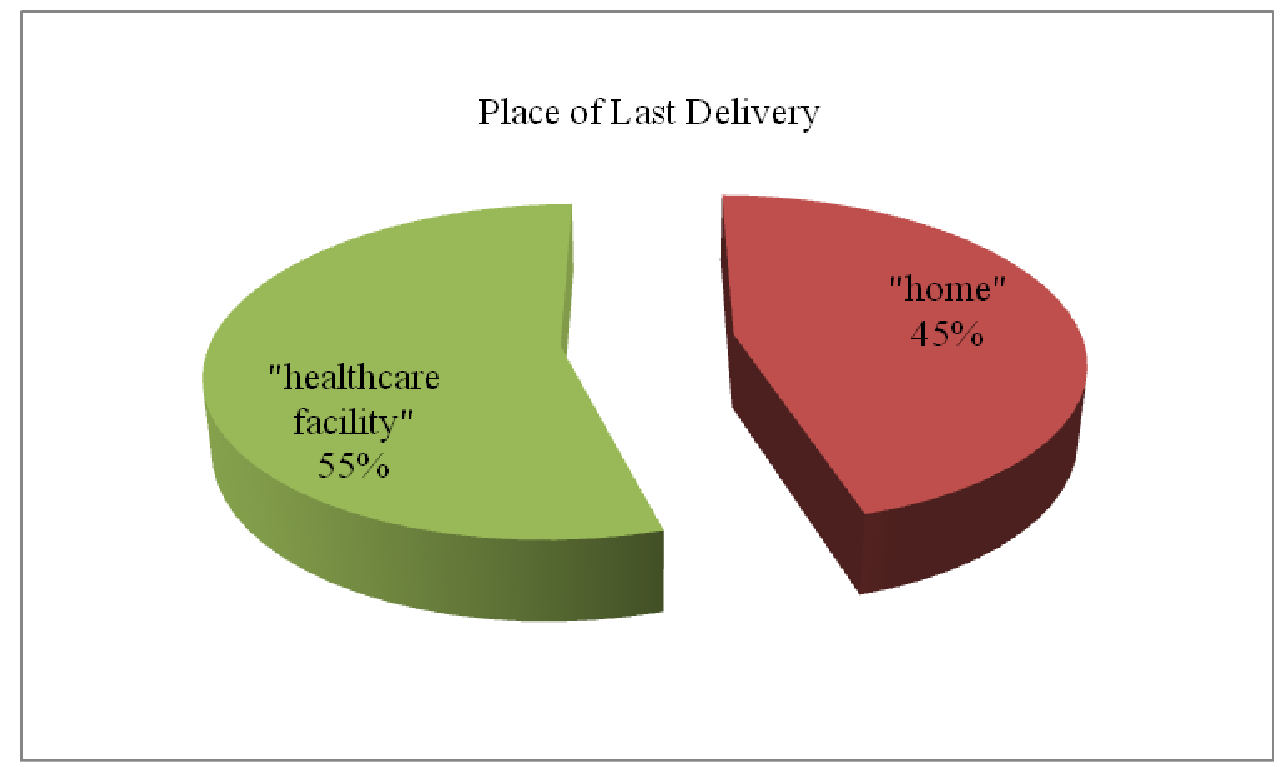

Figure 4: Place of Last Delivery.

\section{Religion}

The results also indicated that religion was a determinant of immunization. The religion that many of the mothers ascribed to was protestant $(68.9 \%)$. The findings indicated a significant association between religious affiliation and full immunization of a child, P-Value $=0.001$. Table 1 below; (Distribution of Religious Affiliation) illustrates the distribution of religious affiliation.

Distribution of Religious Affiliation

\begin{tabular}{lll}
\hline Religion & Frequency & Percent \\
\hline Catholic & 81 & 18.37 \\
Protestant & 304 & 68.93 \\
Muslim & 2 & 0.45 \\
Others & 54 & 12.24 \\
Total & 441 & 100.00 \\
\hline
\end{tabular}

\section{Postnatal Clinic Attendance}

The other identified determinant was not attending postnatal services. There was also a significant association between uptake of postnatal clinic attendance and full immunization of a child; P-Value $=0.023$. Seventy four percent $(74 \%)$ of mothers attended postnatal clinic.

\section{Qualitative Analysis}

The qualitative data from key informant interviews revealed that lack of knowledge on dangers of childhood immunizable diseases, inadequate immunization health messages to mothers, immunization clinic defaults and negative attitudes by staff towards mothers determined immunization coverage. Some of the key informants had this to say, "There is incomplete immunization of infants, mothers default after BCG \& $1^{\text {st }}$ polio”. (KII -Facility incharge).

"Mothers are ignorant of immunization schedule and there is low turn up for hospital delivery" (KII- Facility incharge).

The mothers had this to say, "The immunization services offered are very poor and the staff have negative attitude towards us (clients), staff ignore patients and do not pay attention to our health 
needs and concerns". (FGD woman participant).

\section{Discussion}

Use of immunization is a key strategy for improving child survival whereas a low rate of immunization coverage is indicative of poor health status. Despite a well-established and supported Kenya Expanded Programme on Immunization (KEPI), immunization coverage in Migori County is still low (70\%); a reverse of gains made to positively influence child survival and achievement of millennium development goal number four. This is evidenced by the regions' high infant mortality rate of 95 deaths per 1000 live births and the under fives 149 deaths per 1000 live births. The national infant mortality rate is 52 deaths per 1000 births (KHDS 2008-2009).

Due to relatively high percentage of home deliveries $(45 \%)$ and absence of adequate post-partum visits the mothers miss opportunities to have their infants immunized which in turn contribute to low immunization coverage. In addition the mothers suffer missed opportunities on health messages regarding importance of protecting a child against childhood immunizable diseases. The background information indicates that the topography of the area facilitates poverty since economic opportunities are limited. This back ground plays a role in determinants of immunization in regard to accessibility and utilization. The mother's means of transport to the immunization facility was an associated determinant to immunization coverage. Since the commonest means was on foot and the area experiences high humidity mothers may find it a challenge reaching the immunization sites while carrying their babies. This finding is similar to that of Owino et.al (2009) in their study on factors influencing immunization coverage in Mathare Valley Nairobi. They also identified means of transport and distance to immunization facilities as determinants of immunization coverage.

There is evidence from WHO /UNICEF (2013) that children in poor households are deprived of their rights in many ways, including immunization services. The topographic information and occupation tallies from the survey indicate that poverty index in many households is high. These factors are likely to contribute to low immunization coverage. Poverty deprives a human being of essential elements of dignified livelihood such as basic education.

\section{Conclusion}

The overall immunization coverage is below the National and County targets. The challenges mothers face to meet their obligation of taking their children for immunization included: means of transport, religion, not attending postnatal services, lack of information on dangers of childhood vaccine preventable diseases and delivering at home. Increasing immunization coverage and achieving the national target in Migori County depends therefore upon empowering women through education, economic activities and strengthened post-partum visits for infant immunization.

The health care service providers need to incorporate both outreach and mobile immunization services into the current static module so as to reach the un- reached mothers and their infants. 
Further exploration on the significant association between religion and immunization coverage is recommended. This is in view of the fact that $68.9 \%$ of the mothers were Protestants.

\section{Acknowledgements}

The authors would like to acknowledge the immense contributions made by the following:

1. Canadian Government, Department of Foreign Affairs, Trade and
Development (DFATD) Canada for funding the MAISHA project.

2. College of the Rockies Kranbrook Canada for collaboration and linkage to DFATD

3. Dedan Kimathi University of Technology (DeKUT) management.

4. Ministry of Health $(\mathrm{MOH})$ Migori County for hospitality and assistance in household survey guide.

5. Homabay Kenya Medical Training Centre (KMTC) for data enumeration

MAP OF MIGORI COUNTY: County Administrative and Political Units.

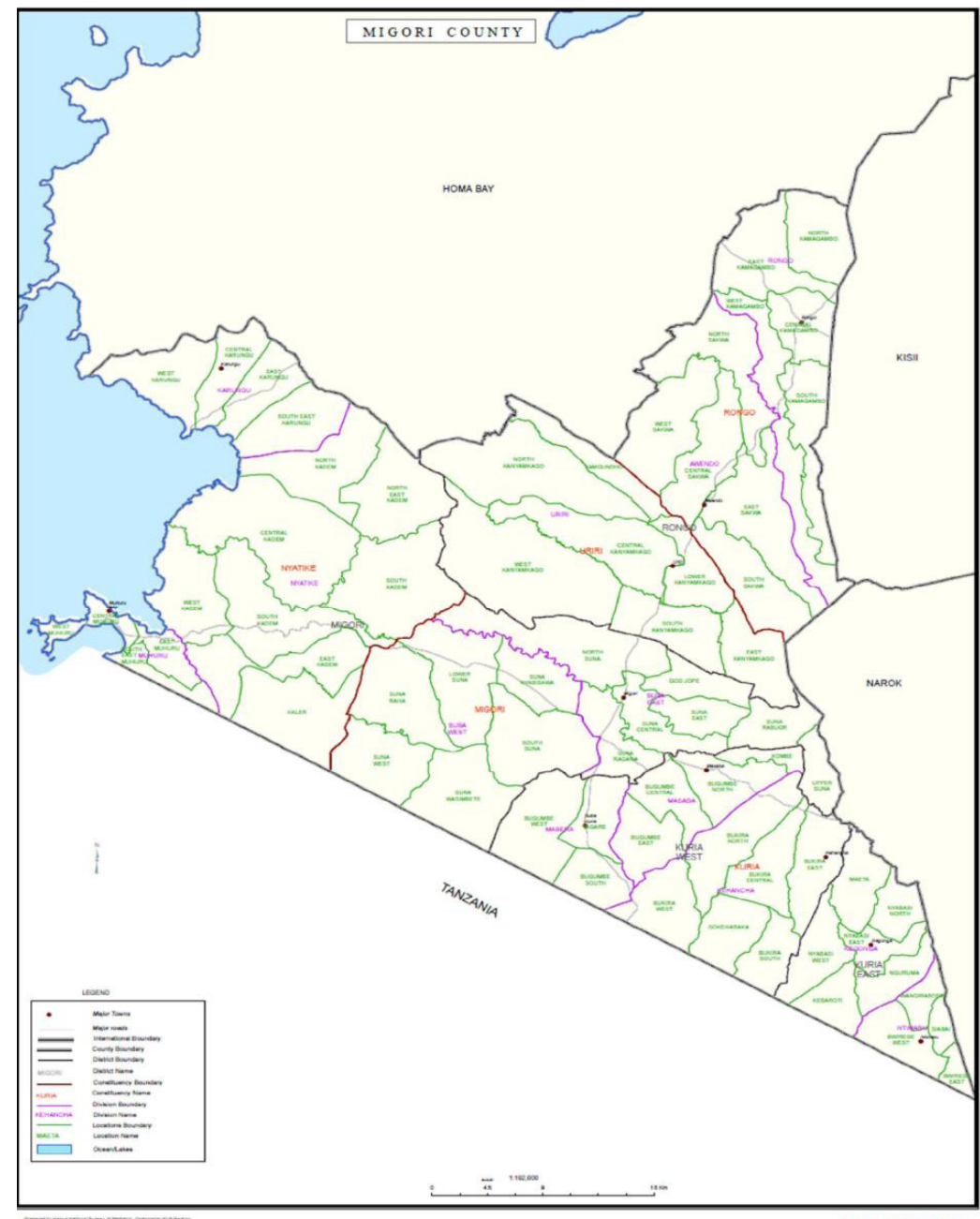

Source: KNBS, 2012 


\section{References}

Centres for Disease Control and Prevention (CDC) (1999). Ten great public health achievements. United States 1900-1999. MMWR Morb Mortal Wkly Rep.; 48: 241243. Kenya

Kenya KNBS, (2013). Nyanza Province Multiple Indicator Cluster Survey 2011, final report, Nairobi, Kenya National Bureau of Statistics

Kenya National Bureau of Statistics (KNBS). and ICF Macro. 2010. Kenya Demographic and Health Survey 2008-09. Calverton, Maryland: KNBS and ICF Macro.

Kenya population and human Census, (2009). www. Knbs .or. ke / index . php? Population distribution.

KNBS Office, (Migori 2013). Statistical Abstract 2013: KNBS, www .knbs .or .ke / index . php ? ...2013

Owino, L.O., Irimu. G., Olenja. J. and Meme, J.S. (2009). Factors influencing immunization coverage in Mathare Valley, Nairobi. East African Medical Journal, 86(7): 323-329.

UNICEF (2014), Progress for Children: Achieving the MDGs with Equity 2010, Number 9, New York,

WHO (2014). Infant mortality rate, under-five mortality rate: United Nations Inter-agency Group for Child Mortality Estimation (IGME),

WHO and UNICEF (2014). Every Newborn: An Action Plan to End Preventable Deaths, WHO, Geneva,

WHO and UNICEF (2014). Estimates of National Immunization Coverage 1980-2013, from United Nations website:

www.un,org/...//pdf/...mdg_report_ $\underline{2013}$

WHO (2005). Global immunization vision and strategy, 2006-2015. Geneva: $\quad$.wholibdoc.who int/hq/2005/WHO-IVB-0.5-0.5.pdf

Ethiopian Journal of Environmental Studies \& Management 9(5): 613 - 624, 2016. 